Original Research Article

\title{
Comparison of ranibizumab and bevacizumab for macular edema associated with retinal vein occlusion
}

\author{
Sharma N. ${ }^{1}$, Jat N.S. ${ }^{2}$, Singh P. ${ }^{3}$, Kumar K. ${ }^{4}$ \\ ${ }^{1}$ Dr. Nupur Sharma, Senior Resident, ${ }^{2}$ Dr. Neha Singh Jat, Junior Resident, ${ }^{3}$ Dr. Priti Singh, Assistant Professor, ${ }^{4}$ Dr. Kavita \\ Kumar, Professor and HOD, all authors are affiliated with Department of Ophthalmology, Gandhi Medical College, Bhopal, \\ Madhya Pradesh, India.
}

Corresponding Author: Dr. Neha Singh Jat, Junior resident, Department of Ophthalmology, Gandhi Medical College, Bhopal, Madhya Pradesh, India. Email: nehasinghjat@gmail.com

\begin{abstract}
Purpose: To assess the effectiveness of intravitreal ranibizumab compared with bevacizumab for the treatment of macular edema associated with retinal vein occlusion (RVO). Methods: This was a retrospective study of 64 eyes with macular edema associated with RVO. Patients received either $1.25 \mathrm{mg}$ of intravitreal bevacizumab $(\mathrm{n}=32)$ or $0.5 \mathrm{mg}$ of intravitreal ranibizumab $(\mathrm{n}=32)$. Visual acuity, clinical bio-microscopic examination and central macular thickness (CMT) by Optical Coherence Tomography (OCT) was assessed at 6 weeks post injection. The CMT before and six weeks after the injection as assessed by OCT were compared. Statistical analysis was performed using paired student t-test. The improvement in CMT was also compared between the two groups, statistical analysis was performed using un-paired student t-test. Results: The best-corrected visual acuity significantly improved from logarithm of the minimal angle of resolution ( $\log M A R) 0.792 \pm 0.36$ at baseline to $0.575 \pm 0.34$ at 6 weeks in the bevacizumab group $(p=0.001)$ and from $\operatorname{logMAR} 0.851 \pm 0.35$ at baseline to $0.336 \pm 0.20$ at 6 weeks in the ranibizumab group $(p=0.001)$, which is statistically significant difference. The reduction in CMT was from $545.44 \pm 176.43$ $\mu \mathrm{m}$ at baseline to $378.34 \pm 95.13$ at 6 weeks in the bevacizumab group $(p=0.001)$ and $524.25 \pm 195.94 \mu \mathrm{m}$ at baseline to $243 \pm 80.72 \mu \mathrm{m}$ at 6 weeks in the ranibizumab group $(p=0.001)$ which was also a statistically significant difference $(p=0.001)$. Conclusions: Both ranibizumab and bevacizumab were effective for the treatment of RVO. The visual outcome and reduction in macular thickness was better by ranibizumab at the earliest follow-up of 6 weeks.
\end{abstract}

Keywords: Bevacizumab, Retinal vein occlusion, Macular edema, Ranibizumab

\section{Introduction}

Macular edema due to retinal vein occlusion (RVO) is the second most common type of retinal vascular diseases after diabetic retinopathy [1] Patients with RVO usually present with progressive diminution of vision mainly due to macular edema [2]. Although branch retinal vein occlusion (BRVO) is the most prevalent type $(0.44 \%)$ compared to central retinal vein occlusion (CRVO) $(0.08 \%)$, significant vision loss caused by macular edema secondary to CRVO is more frequent [3]. Recently, anti-vascular endothelial growth factor (VEGF) therapy has become the treatment of choice for this ocular disorder [4].

The Collaborative Branch Vein Occlusion Study (BVOS) reported that grid argon laser photocoagulation was useful in the treatment of macular edema from BRVO, but the Central Vein Occlusion Study (CVOS) did not show a similar benefit in CRVO [5]. More recent studies

Manuscript received: $14^{\text {th }}$ October 2019

Reviewed: $24^{\text {th }}$ October 2019

Author Corrected: $30^{\text {th }}$ October 2019

Accepted for Publication: $5^{\text {th }}$ November 2019 employing intravitreal injection of steroids have shown a benefit in patients with CRVO as well as BRVO [6]. Vascular endothelial growth factor (VEGF) inhibitors have a more favourable safety profile and have been widely used for the treatment of age related macular degeneration. Ranibizumab was shown in several randomized prospective trials to be effective and was the first VEGF inhibitor to be FDA approved for use in RVO [7]. Bevacizumab has also been shown to be effective in multiple trials and is currently being used off-label [8]. In the present study, the comparison of the effectiveness of ranibizumab and bevacizumab in treating retinal vein occlusion with macular edema was observed by comparing best corrected visual acuity BCVA, central macular thickness before treatment and after 6 weeks of treatment.

\section{Material and Methods}

Study type: Prospective Observational study Duration of study: December 2017- December 2018 


\section{Original Research Article}

Sample size: Patients with RVO attending out-patient department.

\section{Inclusion criteria}

1) Patients diagnosed with macular edema due to RVO of less than 6 months duration. Both BRVO and CRVO were eligible.

2) CMT greater than $250 \mu \mathrm{m}$ on spectral domain optical coherence tomography (SD-OCT).

3) BCVA between 0.3 logarithm of the minimal angle of resolution (logMAR) and $1.2 \log$ MAR .

\section{Exclusion criteria}

1) Non ischemic type

2) No pre-existing glaucoma or ocular hypertension

3) No history of prior laser or intravitreal injections.

4) Presences of any other macular pathology, such as agerelated macular degeneration or diabetic retinopathy.

5) Any history of intraocular surgery in the study eye

Data collection procedure: This was a prospective observational study where data was collected in Predesigned Performa at the end of the study duration it was analyzed.

Data analysis: Data was compiled using MS excel and analyzed using SPSS software version 20. Frequency for grouped variable was calculated and expressed as percentage. Association between variables were assessed using CHI Square Test and confidence interval. P value less than 0.05 was considered significant whereas 0 value less than 0.01 was considered highly significant.

\section{Ethical consideration and permission}

Study was approved by institutional ethical committee. Well informed and written consent was obtained from the patient.

\section{Methods}

A total 64 eyes in 64 patients were included, they were divided in to two groups, eyes that received ranibizumab for the treatment of macular edema $(\mathrm{N}=32)$, and those that received bevacizumab $(\mathrm{N}=32)$.

All patients were examined at baseline, $1^{\text {st }}, 3^{\text {rd }}$, and $6^{\text {th }}$ week after the first treatment. The first examination included collection of data about the duration of occlusion, previous eye diseases (interventions), existence of other systemic diseases, such as cardiovascular diseases, systemic hypertension, diabetes, thrombosis and so on.

The ophthalmic examination included determination of best-corrected visual acuity (BCVA) in Snellen's decimal units (converted to log of the minimum angle of resolution [logMAR] units), intraocular pressure (IOP) measurement by Goldman's applanation tonometer, anterior segment evaluation by slit-lamp biomicroscopy and posterior segment examination with indirect ophthalmoscopy with 20 D lens, description of the type of occlusion (CRVO or BRVO) and the findings of the fundus.

The diagnosis was confirmed by fundus fluorescein angiography (FFA) and OCT of the macula (Topcon 3D OCT-2000), whereby the central macular thickness (CMT) was measured in microns. In addition, before the first injection, the following parameters of the general status were determined: differential blood count (platelets), lipid status, blood glucose and blood pressure. Intravitreal ranibizumab and bevacizumab injections were performed in the operating room under sterile conditions.

Topical anesthetic drops were given first and then a lid speculum was inserted. The injection site was cleaned with $5 \%$ povidone iodine, $0.5 \mathrm{mg}(0.05 \mathrm{~mL})$ ranibizumab or 1.25 $\mathrm{mg}(0.05 \mathrm{~mL})$ bevacizumab was injected via the pars plana with a 30 -gauge needle, $4 \mathrm{~mm}$ away from the limbus in phakic patients.

The needle was carefully removed using a sterile cotton applicator to prevent reflux. Indirect ophthalmoscopy and tonometry were performed after the procedure to detect any injection-related complications. After the injection, antibiotic eye drops were applied every 6 hours for 1 week.

\section{Results}

Table-1: Demographic distribution of Study subjects according to used drugs and gender.

\begin{tabular}{|c|c|c|c|}
\hline Gender & Group I (BVZ) & Group II (RBZ) & TOTAL \\
\hline MALE & 25 & 20 & 45 \\
\hline FEMALE & 7 & 12 & 64 \\
\hline TOTAL & 32 & 64.28 Year & \\
\hline Mean Age (Year) & 63.74 Year & 1.871 \\
\hline Chi Square Value & \multicolumn{3}{|c}{$0.171(\mathrm{NS})$} \\
\hline Significance 'p' Value &
\end{tabular}




\section{Original Research Article}

Table 1 reveals demographic distribution of study subjects according to used drugs and gender. Total 64 patients were selected for the study and they were randomly divided in to two groups with 32 patients in each group. Patients in group 1 were given BVZ and group 2 were given RBZ. Out of 64 patients 45 were male and 19 were female. There was no statistically significant difference found in distribution of study subjects according to used drugs and gender $(\mathrm{p}=0.171)$.

Table-2: Comparative evaluation of Visual acuity in Log MAR between group I (BVZ) and group II (RBZ).

\begin{tabular}{|c|c|c|c|}
\hline Groups & N & Visual Acuity at Presentation & Visual Acuity at 6 weeks \\
\hline & & Mean \pm SD & Mean \pm SD \\
\hline Group I (BVZ) & 32 & $\mathbf{0 . 7 9 2} \pm \mathbf{0 . 3 6}$ & $\mathbf{0 . 5 7 5} \pm 0.34$ \\
\hline Group II (RBZ) & 32 & $\mathbf{0 . 8 5 1} \pm \mathbf{0 . 3 5}$ & $\mathbf{0 . 3 3 6} \pm \mathbf{0 . 2 0}$ \\
\hline Unpaired Student 't' test Value & & $\mathbf{0 . 6 4 5}$ & $\mathbf{3 . 3 5 0}$ \\
\hline Significance 'p' Value & & $\mathbf{0 . 5 2 1 ( N S )}$ & $\mathbf{0 . 0 0 1 ( H S )}$ \\
\hline
\end{tabular}

Table 2 reveals comparative evaluation of visual acuity in Log MAR between group I (BVZ) and group II (RBZ). There was statistically no significant difference in visual acuity at the time of presentation $(p=0.521)$. Mean visual acuity was better in group II patients as compare to group I patients at 6 weeks. It was $0.575 \pm 0.34 \& 0.336 \pm 0.20$ in group I \& group II patients respectively at 6 weeks. Unpaired student ' $t$ ' test was applied to find significance difference between groups. There was statistically significant difference found in mean visual acuity at 6 week between group I \& II $(p=0.001)$.

Table-3: Comparative evaluation of visual acuity in Log MAR from time of presentation to 6 weeks among group I (Bevacizumab) and group II (Ranibizumab).

\begin{tabular}{|c|c|c|c|c|}
\hline Groups & $\begin{array}{c}\text { Visual Acuity at } \\
\text { Presentation }\end{array}$ & $\begin{array}{c}\text { Visual Acuity at } 6 \\
\text { weeks }\end{array}$ & $\begin{array}{c}\text { Paired } \\
\text { student 't' } \\
\text { test Value }\end{array}$ & $\begin{array}{c}\text { Significance } \\
\text { ' } p \text { ' Value }\end{array}$ \\
\cline { 1 - 3 } Group I (Bevazimuab) & $\mathbf{0 . 7 9 2} \pm \mathbf{0 . 3 6}$ & $\mathbf{0 . 5 7 5} \pm \mathbf{0 . 3 4}$ & $\mathbf{3 . 8 1 2}$ & $\mathbf{0 . 0 0 1 ( H S )}$ \\
\hline Group II (Ranibizumab) & $\mathbf{0 . 8 5 1} \pm \mathbf{0 . 3 5}$ & $\mathbf{0 . 3 3 6} \pm \mathbf{0 . 2 0}$ & $\mathbf{9 . 1 4 5}$ & $\mathbf{0 . 0 0 1 ( H S )}$ \\
\hline
\end{tabular}

Table 3 reveals Comparative evaluation of visual acuity in LogMAR from time of presentation to 6 week among group I (Bevacizumab) and group II (Ranibizumab). There was statistically significant improvement in visual acuity from time of presentation to 6 weeks among both the groups $(\mathrm{p}=0.001$ ). Visual acuity had improved from $0.792 \pm 0.36$ to $0.575 \pm 0.34$ in group I and from $0.851 \pm 0.35$ to $0.336 \pm 0.20$ in group II. Paired student ' $t$ ' test was applied to find significant difference.

Table-4: Comparative evaluation of Central macular thickness (CMT) between group I (BVZ) and group II (RBZ).

\begin{tabular}{|c|c|c|c|}
\hline Groups & N & $\begin{array}{c}\text { CMT at Presentation } \\
(\boldsymbol{\mu m})\end{array}$ & CMT at 6 week $(\boldsymbol{\mu m})$ \\
\hline & & Mean \pm SD & Mean \pm SD \\
\hline Group I (BVZ) & 32 & $\mathbf{5 4 5 . 4 4} \pm \mathbf{1 7 6 . 4 3}$ & $\mathbf{3 7 8 . 3 4} \pm \mathbf{9 5 . 1 3}$ \\
\hline Group II (RBZ) & 32 & $\mathbf{5 2 4 . 2 5} \pm \mathbf{1 9 5 . 9 4}$ & $\mathbf{2 4 3 . 7 5} \pm \mathbf{8 0 . 7 2}$ \\
\hline Unpaired Student 't' test Value & & $\mathbf{0 . 4 5 5}$ & $\mathbf{6 . 1 0 2}$ \\
\hline Significance 'p' Value & & $\mathbf{0 . 6 5 1 ( N S )}$ & $\mathbf{0 . 0 0 1 ( H S )}$ \\
\hline
\end{tabular}

Table 4 reveals comparative evaluation of CMT between group I (BVZ) and group II (RBZ). There was statistically no significant difference in macular thickness at the time of presentation $(\mathrm{p}=0.651)$. Mean macular thickness was higher in group I patients as compare to group II patients at 6 weeks.

It was $378.34 \pm 95.13 \& 243.75 \pm 80.72$ in group I \& group II patients respectively. Unpaired student ' $t$ ' test was applied to find significance difference between groups. There was statistically significant difference found in mean CMT at 6 weeks between group I \& II $(\mathrm{p}=0.001)$. 
Original Research Article

Table-5: Comparative evaluation of CMT from time of presentation to 6 weeks among group I (BVZ) and group II (RBZ).

\begin{tabular}{|c|c|c|c|c|}
\hline Groups & $\begin{array}{c}\text { CMT at Presentation } \\
(\boldsymbol{\mu m})\end{array}$ & CMT at 6 week $(\boldsymbol{\mu m})$ & $\begin{array}{c}\text { Paired student ' } \mathbf{t} \text { ' } \\
\text { test Value }\end{array}$ & $\begin{array}{c}\text { Significance } \\
\text { 'p' Value }\end{array}$ \\
\cline { 1 - 2 } & Mean $\pm \mathrm{SD}$ & Mean $\pm \mathrm{SD}$ & 4.716 & $0.001(\mathrm{HS})$ \\
\hline Group I (BVZ) & $545.44 \pm 176.43$ & $378.34 \pm 95.13$ & 11.563 & $0.001(\mathrm{HS})$ \\
\hline Group II (RBZ) & $524.25 \pm 195.94$ & $243.75 \pm 80.72$ & \\
\hline
\end{tabular}

Table 5 reveals Comparative evaluation of CMT in micron meter from time of presentation to 6 weeks among group I (BVZ) and group II (RBZ). There was statistically significant reduction was found in CMT from time of presentation to 6 weeks among both the groups ( $\mathrm{p}=0.001$ ). CMT was reduced from $545.44 \pm 176.43$ to $378.34 \pm 95.13$ micrometer in group I and $524.25 \pm 195.94$ to $243.75 \pm 80.72$-micron meter in group II. Paired student ' $t$ ' test was applied to find significant difference.

\section{Discussion}

RVO occurs due to blockage of the retinal vein that carries blood away from the retina. Macular edema is the most common and serious complication of RVO, causing vision loss [9]. Currently treatment of RVO is aimed at the reducing macular oedema, which is the leading cause of vision loss [10]. Various literature has demonstrated vascular occlusion-related retinal ischemia leading to increased vascular permeability, leakage, neovascularization and vasodilation in patients with RVO $[11,12]$.

Long-lasting macular oedema usually produces secondary retinal pigment epithelial (RPE) changes, which themselves result in poor visual acuity Although various treatment modalities are available for the treatment of retinal vein occlusion, antiVEGF agents remain the mainstay of treatment and their efficacy have been demonstrated in various studies. The present study aimed at comparing the treatment efficacy of Ranibizumab and Bevacizumab for Macular Edema associated with Retinal Vein Occlusion. Patients in two randomly allocated groups were comparable in terms of sociodemographic variables.

At presentation, there was statistically no significant difference in visual acuity between the patients of two groups $(p=0.521)$. Though mean visual acuity improved significantly in patients of both the groups following treatment $(p<0.01)$ but improvement was significantly better in the patients of Ranibizumab group as compared to bevacimumab group $(p<0.01)$. Anti-VEGF injections by decreasing the macular edema improves the macular function and thus improves the visual acuity. These findings were in contrast to the findings of Son BK et al in which significant improvement in visual acuity was observed in both the groups at 6 month follow up as compared to baseline but the difference in improvement of visual acuity between the groups was statistically not significant [9]. Qian $\mathrm{T}$ et al in their study compared the efficacy and safety of drug therapies (aflibercept, ranibizumab, bevacizumab, pegaptanib, dexamethasone, triamcinolone) for macular edema secondary to central retinal vein occlusion and observed that only aflibercept and ranibizumab had a significantly better efficacy than the sham/placebo group [13]. The BRAVO trial assessed the efficacy of ranibizumab in patients with $\mathrm{BRVO}$ and found a significant improvement in visual acuity and a reduction in central foveal thickness in the ranibizumab-treated group compared to a sham group [13].

Narayanan et al [14] (level I) reported a prospective, randomized, noninferiority trial comparing ranibizumab $(\mathrm{n}=37)$ and bevacizumab $(\mathrm{n}=38)$ in BRVO. Seventy-five participants were enrolled and randomly assigned to $0.5 \mathrm{mg}$ ranibizumab or $1.25 \mathrm{mg}$ bevacizumab.

Patients were treated at baseline and retreated on a PRN regimen based on the presence of diffuse persistent edema in the central subfield or a $>50 \mu \mathrm{m}$ increase in CRT on spectral-domain OCT from the lowest previous measurement. Both groups experienced significant gains in VA $(+18.1$ letters for ranibizumab, +15.6 letters for bevacizumab). In addition, there was a significant reduction in CRT in both groups $(-177.1 \mu \mathrm{m}$ in the ranibizumab group, -201.7 in the bevacizumab group). There were no significant functional or anatomic differences between the 2 groups. The mean number of injections was similar in both groups.

Rajagopal et al [15] in CRAVE study (Bevacizumab vs Ranibizumab in the treatment of macular edema due to retinal vein occlusion) compared efficacy of monthly ranbizumab or bevacizumab for RVO-ME in a randomised clinical traal. After six months, changes in central macular thickness and visual acuity were not different between the treatment groups. Although the efficacy of ranibizumab and bevacizumab are reported to be quite similar in the treatment of CRVO-ME in many studies, the use of bevacizumab in the management of RVO-ME remains off labels. 
Original Research Article

In a prospective randomized clinical trial by MARVEL group, the efficacy of IVB and ranibizumab (IVR) in BRVO-ME was compared. The number of injections was not significantly different between the treatment groups (3.2 \pm 1.5 versus $3.0 \pm 1.4$, respectively; $\mathrm{P}=0.55)$. There was a significant improvement in VA and CMT in eyes that underwent either bevacizumab or ranibizumab injection without any significant difference between the two drugs [14].

The Central macular thickness represents anatomic changes in the fovea after treatment [16]. Yuan A et al concluded that ranibizumab is associated with improved anatomic results with decreased cystoid macular edema and a trend towards decreased macular thickness, the functional change was not significant as compared to bevacizumab [17].

In present study, central macular thickness was comparable in both the groups at presentation. Following treatment, highly significant reduction in CMT was observed amongst the patients of both the groups as compared to CMT reading at presentation $(\mathrm{p}<0.01)$ but the reduction in CMT was significantly higher in patients of Ranibizumab group as compared to Bevacizumab group $(\mathrm{p}<0.01)$.

These findings were contrasting to the findings of Son BK et al in which significant reduction in CMT was observed in both the groups at 6 month follow up but the observed difference was statistically not significant between the groups [9]. Qian T et al reported ranibizumab to be more effective in reducing CRT at 6 months than dexamethasone, and bevacizumab was more effective than than triamcinolone but less effective than Ranibizumab [13].

Sangroongruangsri S et al could not identify the significant difference in BCVA improvement and CMT reduction among patients treated with Bevacizumab, ranibizumab and aflibercept [18]. The BRAVO trial assessed the efficacy of ranibizumab in patients with BRVO and found a significant improvement in visual acuity and a reduction in central foveal thickness in the ranibizumab-treated group compared to a sham group [16].

Study Limitations: In the present study had certain limitations such as small sample size and short duration of follow up. However, a detailed study with longer follow up to asses efficacy of these treatment modalities in long run would yield better picture.

\section{Conclusions}

Both ranibizumab and bevacizumab were effective for the treatment of RVO. The visual outcome and reduction in macular thickness was better by ranibizumab at the earliest follow-up of 6 weeks.

\section{What the study adds to the existing knowledge?}

Efficacy of ranibizumab was observed to be better than bevacizumab in reduction of macular thickness in RVO patients.

\section{Author's contribution}

Dr. Nupur Sharma: Collaborated on the concept, data collection, data analysis and manuscript preparation.

Dr. Neha Singh Jat: Collaborated on the concept, data collection, data analysis and manuscript preparation.

Dr. Priti Singh: Collaborated on the concept, data collection, data analysis and manuscript preparation.

Dr. Kavita Kumar: Conceptualization, data analysis and manuscript preparation

Funding: No funding sources

Conflict of interest: None declared

Ethical Approval: This study was approved by the Institutional Ethics Committee

\section{Reference}

1. Brand CS. Management of retinal vascular diseases: a patient-centric approach. Eye (Lond). 2012;26(2):S1-16. doi: 10.1038/eye.2012.32.

2. The International Federation on Ageing. Treating retinal diseases in the era of anti-VEGF therapies. 2016:[14 p.]. Available from: https:/www.ifa-fiv.org/wp-content/ uploads / 2016/ 10/Treating-Retinal-Diseases-in-the-Eraof-Anti-VEGF-therapiesPosition-Paper-Final.pdf .

3. Ip MS, Scott IU, VanVeldhuisen PC, Oden NL, Blodi BA, Fisher M, et al. A randomized trial comparing the efficacy and safety of intravitreal triamcinolone with observation to treat vision loss associated with macular edema secondary to central retinal vein occlusion: the Standard Care vs Corticosteroid for Retinal Vein Occlusion (SCORE) study report 5. Arch Ophthalmol. 2009;127 (9): 1101-1114. doi: 10.1001/archophthalmol.2009.234.

4. Campochiaro P, Brown DM, Awh CC, Lee SY, Gray S, Saroj N, et al. Sustained benefits from ranibizumab for macular edema following central retinal vein occlusion: twelve-month outcomes of a phase III study. Ophthalmol. 2011; 118(10):2041-2049. doi: 10.1016/j.ophtha.2011.02. 038. Epub 2011 Jun 29.

5. Pieramici DJ, Rabena M, Castellarin AA, Nasir M, See $\mathrm{R}$, Norton $\mathrm{T}$, et al. Ranibizumab for the treatment of macular edema associated with perfused central retinal vein occlusions. Ophthalmol. 2008;115(10):e47-e54. doi: 10. 1016/ j. ophtha.2008.06.021. Epub 2008 Aug 16. 
Original Research Article

6. Figueroa MS, Contreras I, Noval S, Arruabarrena C. Results of bevacizumab as the primary treatment for retinal vein occlusions. Br J Ophthalmol. 2010;94(8):1052-1056. doi: 10.1136/bjo.2009.173732.

7. Gregori NZ, Rattan GH, Rosenfeld PJ, Puliafito CA, Feuer W, Flynn HW Jr, et al. Safety and efficacy of intravitreal bevacizumab (avastin) for the management of branch and hemiretinal vein occlusion. Retina. 2009; 29 (7): 913-925. doi: 10.1097/IAE.0b013e3181aa8dfe.

8. Jaissle GB, Leitritz M, Gelisken F, Ziemssen F, BartzSchmidt KU, Szurman P. One-year results after intravitreal bevacizumab therapy for macular edema secondary to branch retinal vein occlusion. Graefes Arch Clin Exp Ophthalmol. 2009;247(1):27-33. doi: 10.1007/s00417-0080916-2. Epub 2008 Aug 12.

9. Son BK, Kwak HW, Kim ES, Yu SY. Comparison of Ranibizumab and Bevacizumab for Macular Edema Associated with Branch Retinal Vein Occlusion. Korean J Ophthalmol. 2017;31(3):209-216. doi: 10.3341/kjo.2015. 0158. Epub 2017 Apr 24.

10. Spooner K, Fraser-Bell S, Hong T, Chang AA. Fiveyear outcomes of retinal vein occlusion treated with vascular endothelial growth factor inhibitors. BMJ open Ophthalmol. 2019;4(1):e000249. doi: 10.1136/bmjophth2018-000249.

11. Karia N. Retinal vein occlusion: pathophysiology and treatment options. Clinical Ophthalmology (Auckland, NZ). 2010;4:809-816. doi:10.2147/OPTH.S7631.

12. Noma $H$, Funatsu $H$, Yamasaki M, Tsukamoto $H$, Mimura T, Sone T, et al. Pathogenesis of macular edema with branch retinal vein occlusion and intraocular levels of vascular endothelial growth factor and interleukin-6. American J Ophthalmol. 2005;140(2):256-e1. doi:10.1016 /j. ajo. 2005.03.003
13. Qian T, Zhao M, Wan Y, Li M, Xu X. Comparison of the efficacy and safety of drug therapies for macular edema secondary to central retinal vein occlusion. BMJ Open. 2018;8(12):e022700. doi: 10.1136/bmjopen-2018-022700.

14. Narayanan R, Panchal B, Das T, Chhablani J, Jalali S, Ali MH; Marvel study group. A randomised, doublemasked, controlled study of the efficacy and safety of intravitreal bevacizumab versus ranibizumab in the treatment of macular oedema due to branch retinal vein occlusion: MARVEL Report No. 1. Br J Ophthalmol. 2015; 99(7):954-959. doi: 10.1136/bjophthalmol-2014-306543. Epub 2015 Jan 28.

15. Rajagopal R, Shah GK, Blinder KJ, Altaweel M, Eliott $\mathrm{D}$, Wee $\mathrm{R}$, et al. Bevacizumab Versus Ranibizumab in the Treatment of Macular Edema Due to Retinal Vein Occlusion: 6-Month Results of the CRAVE Study. Ophthalmic Surg Lasers Imaging Retina. 2015;46(8):844850. doi: 10.3928/23258160-20150909-09.

16. Campochiaro PA, Heier JS, Feiner L, Gray S, Saroj N, Rundle AC, et al. Ranibizumab for macular edema following branch retinal vein occlusion: six-month primary end point results of a phase III study. Ophthalmol. 2010; 117(6):1102-1112.e1. doi: 10.1016/j.ophtha.2010.02.021. Epub 2010 Apr 15.

17. Yuan A, Ahmad BU, Xu D, Singh RP, Kaiser PK, Martin DF, et al. Comparison of intravitreal ranibizumab and bevacizumab for the treatment of macular edema secondary to retinal vein occlusion. Int J Ophthalmol. 2014; 7(1):86-91. doi: 10.3980/j.issn.2222-3959.2014.01.15.

18. Sangroongruangsri $\mathrm{S}$, Ratanapakorn $\mathrm{T}$, Wu $\mathrm{O}$, Anothaisintawee T, Chaikledkaew U. Comparative efficacy of bevacizumab, ranibizumab, and aflibercept for treatment of macular edema secondary to retinal vein occlusion: a systematic review and network meta-analysis. Expert Rev Clin Pharmacol. 2018;11(9):903-916. doi: 10.1080/17512433.2018.1507735. Epub 2018 Aug 10.

\section{How to cite this article?}

Sharma N, Jat N.S, Singh P, Kumar K. Comparison of ranibizumab and bevacizumab for macular edema associated with retinal vein occlusion. Trop J Ophthalmol Otolaryngol.2019;4(7):419-424.doi:10.17511/jooo.2019.i07.04 